\title{
Biometric Attendance for Classrooms - A Real-Time Implementation
}

\author{
Suprakash S, Balakannan S P, Sugumar V R, Manoj Kumar R, Viswanathan K
}

\begin{abstract}
Biometric fingerprint attendance systems have is widely used in a different working sector such as schools, colleges, and industries for monitoring employees. In most of the schools and colleges, the attendance system is still in RFID technology. A replacement of this technology with the Biometric system can be more and more useful in the educational sector for accurate student attendance. The system is very much useful for schools and colleges to generate the attendance of each and every student. Fingerprint access is used to generate attendance. This system can provide an accurate, faster, and convenient way of managing and monitoring the student progress in the classroom. Automatic notification to parents and higher authorities on the student's presence will provide an added advantage over the previous systems.
\end{abstract}

Keywords: Biometric, Attendance System.

\section{INTRODUCTION}

$\mathrm{T}_{\mathrm{l}}$ his study is done to find the feasibility of biometric devices to enable the attendance system in educational organizations. It uses the most reliable way of uniquely identifying students through fingerprint reading through their unique ID. These applications are highly used in monitoring everyday attendance of the students in schools and higher education institutions. There are so much of attendance system which is outdated. Many old methods of taking attendance such as paper sheet, roll calling and card punching are not later on to identify the correct inputs. There are chances where students can misuse the card or give a false attendance for somebody else. Biometric fingerprint attendance systems have a very easy way of check-in and check-out and each time of check-in and check-out noted against the correct student. There are several biometric processes such as eyesight, fingerprint, and RFID devices. Here fingerprint device is used to take attendance of the students this process is very secure and safe easy monitoring. Biometric technology like fingerprint attendance system generate and easily identify the person and introduced short message system. This short message system is very helpful to parents. To find whether their children's attend class or not. Once the student generates their attendance using fingerprint attendance system message sent to parents from check-in to check-out.

Revised Manuscript Received on December 16, 2019.

* Correspondence Author

Suprakash S*, Department of Information Technology, Kalasalingam Academy of Research and Education, Anand Nagar, Krishnankoil, India. Email: s.suprakash@gmail.com

Balakannan S P, Department of Information Technology, Kalasalingam Academy of Research and Education, Anand Nagar, Krishnankoil, India. Email: balakannansp@gmail.com

Sugumar V R, Manoj Kumar R, Viswanathan K, Department of Information Technology, Kalasalingam Academy of Research and Education, Anand Nagar, Krishnankoil, India.

\section{A. Field and Literature Survey}

A survey was made with a different classroom with different strength within the campus. It was found that an average of 40-60 students are available in each class and the time taken to take the attendance is $5-10$ minutes. Also, this is done by calling names and there is a chance that students may give a false attendance for their friends. Another RFID based system was studied with School where students walk-in by showing their cards on the RF reader. It takes approximately 5 seconds for a student to complete the attendance. For a class with 40 to 60 students, it will take an approximate of 3 to 5 minutes. But here to authentication of the card is not assured.

There is a lot of research happening in the biometric attendance system worldwide.[1] used a Zigbee wifi technology to transfer fingerprint data to a Biometric data server. The same can provide access within 30 to 70 meters of range without any problem. If the classroom is within this coverage area can use the system.

An RFID based University attendance system was developed by Kassem et al. [2]. The students have to show an RFID ID card with the reader fixed with the University. This requires the student to show the card near to the devices. A database of the reading is maintained to produce reports. This system fails in making attendance at each classroom since it is maintained centrally. Also, there is a possibility that the students can make a false entry for other students.

[3] Uses a fingerprint reader device to enroll and cross-check the fingerprints. The system is detached and there is no live data that is communicated with higher authorities. To track and verify the details, the data have to be moved to an SD card and then transferred to systems and manipulated in excel sheets.

Even though there are a lot of initiatives for attendance management, there is no timely reporting system that is secure and intelligent. This work studies the feasibility of introducing a fingerprint reader in each class and monitoring the attendance system with the biometric fingerprint data available. Rest of the paper is organized with the architecture, software design, test results, and conclusion.

\section{SYSTEM ARCHITECTURE}

Fingerprints are the easiest technique for biometric identification. The fingerprint recognition process is done in two steps. First, the fingerprint is registered with the scanning device initially. Later the fingerprint is matched with the already available templates and response is recorded. 
figure 1.

The methodological steps of the system are pictured in

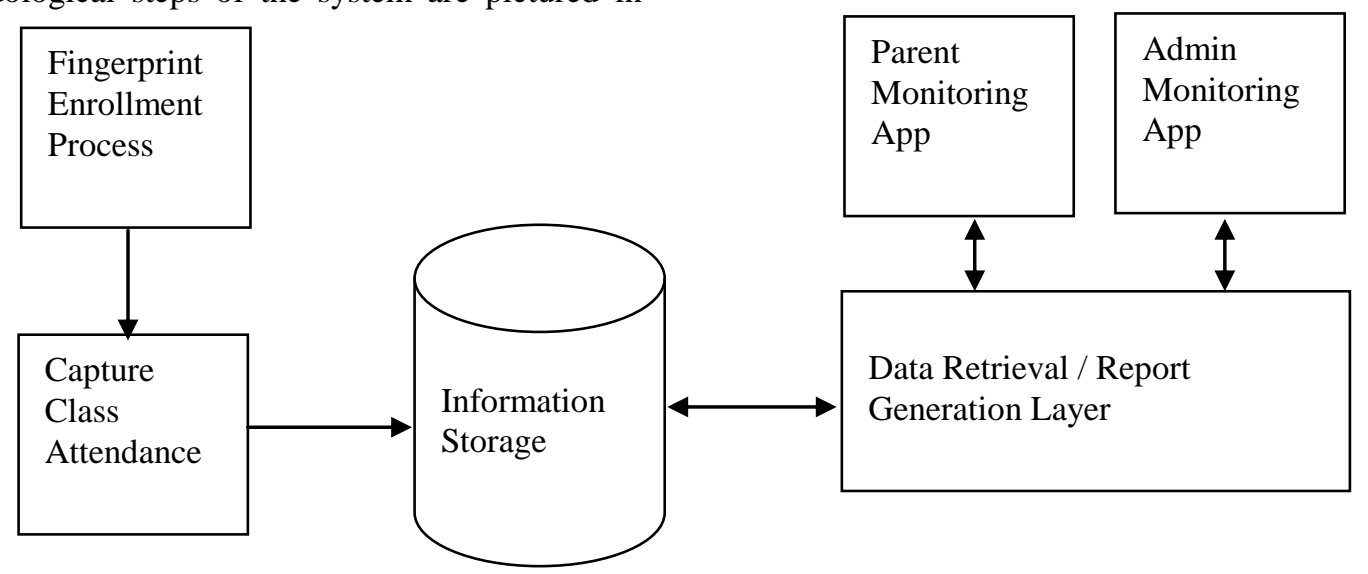

Figure 1: System Architecture

The process has the following modules.

- Fingerprint Enrollment Process

- Capturing Class Attendance

- Information Management

- Data Processing Layer

- Parent Monitoring

- Admin Monitoring

\section{A. Fingerprint enrollment process}

The information base of each and every student is important in maintaining attendance. The initial process is to register the fingerprints of all the students in the system. The same will generate a unique id for each and every fingerprint. The same is mapped with the student register numbers in the database. The student has to scan their fingerprint for enrollment and a confirmation scan is also done to ensure the scanned image is correct.

\section{B. Capturing Class Attendance}

ZKTeco K60 Pro is used to capture the fingerprint of students. The device is capable of storing 10,000 fingerprints and 80,000 transactions. These devices are connected to the server system through Ethernet. Static IP is assigned to each device which uniquely identifies the device and the classrooms. The class timings are configured on the server database.

The attendance capturing starts by reading students fingerprints when they enter into each class sessions. This information is initially stored in the device. Later on, the server triggers to retrieve the captured data at predefined timeslots and the same is updated with the server database.

\section{Information Management}

An SQL server is configured to record all the data related to the student. The devices, the classrooms linked with the device, the time slots for each class/session is maintained in the database. Also, there is a trigger maintained to retrieve the information available in the device and update the same to the central DB.

\section{Data processing layer}

This layer is responsible for providing the required data for the application linked. The query request from the application is processed, corresponding data is generated and populated to the application calling it.

\section{E. Parent / Admin application for monitoring}

An application is designed both for mobile and PC to view the attendance of the students. The admin application has features to alert the higher authorities about the absence of students in the classroom. Also, there is a facility to send text SMS to parents about the absence of the students in the classroom. From the parent login, they can check the student's attendance class wise at any time.

\section{RESULTS AND DISCUSSION}

The system was tested with different sets of students for random sessions. It was found in an average that 3.37 seconds is required for the fingerprint reading including the movement of the student informant of the device. Figure 2 shows the recorded time for 20 students monitored.

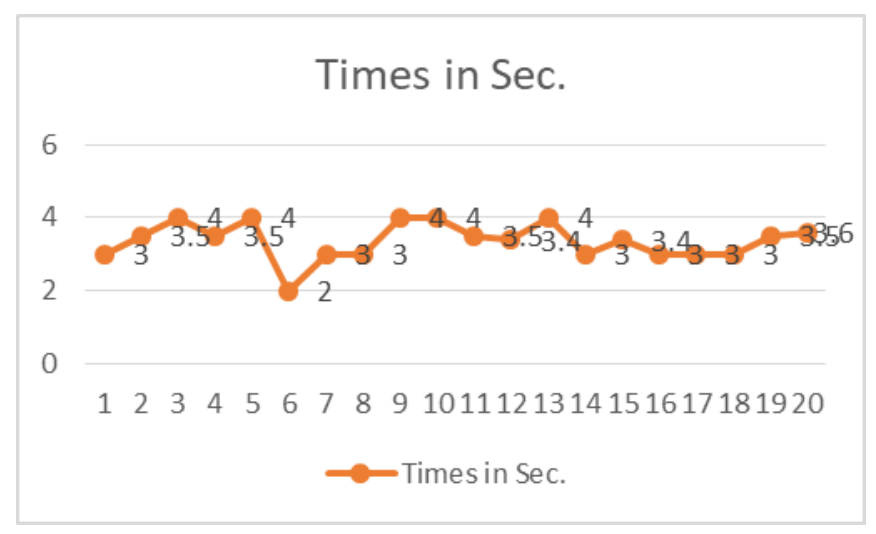

Figure 2: Time for Scan

So on average, the time spent in taking attendance in the classroom for a class strength ranging from 40 to 65 is shown in Figure 4.

Published By: 
The minimum time taken is 2.25 minutes for a class with 40 strength and the maximum time taken is 3.65 minutes with 65 students. This is good compared to the manual system which takes around 4 to 8 minutes on the classrooms as shown in the Figure 5. Also since this is biometric the error for false entry

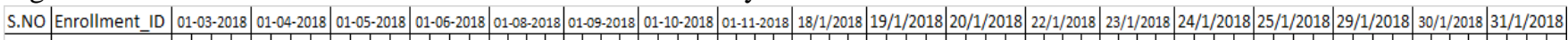

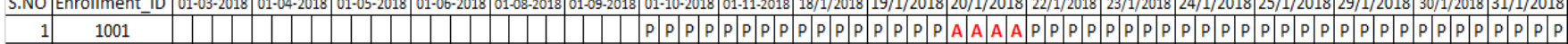

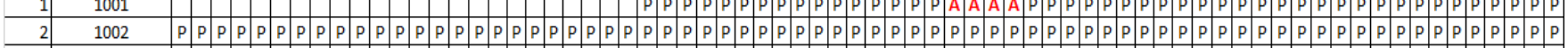

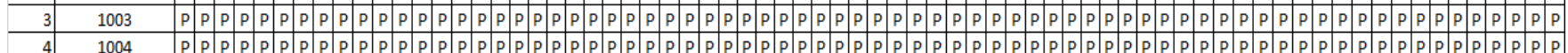

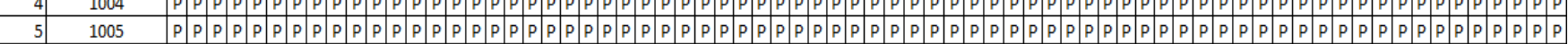

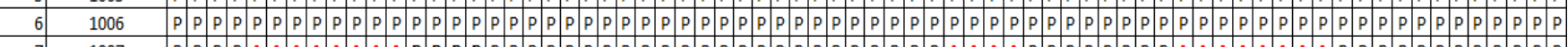

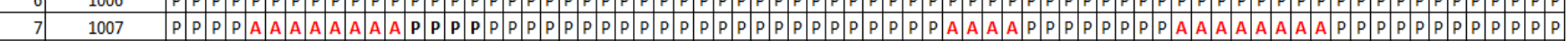

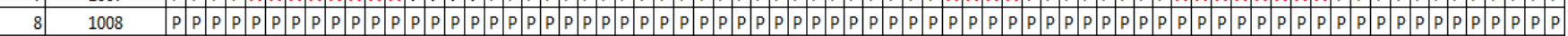

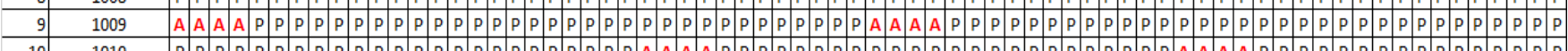

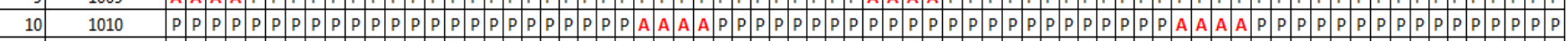

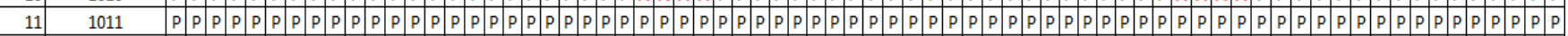

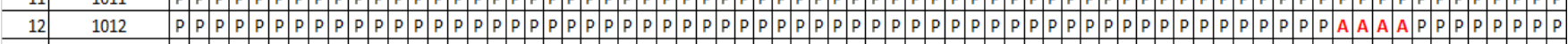

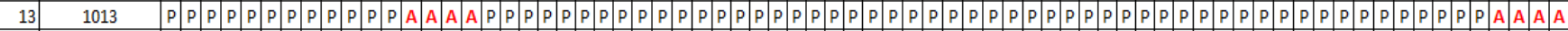

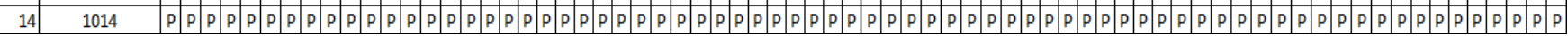
Figure 3: Database Entries

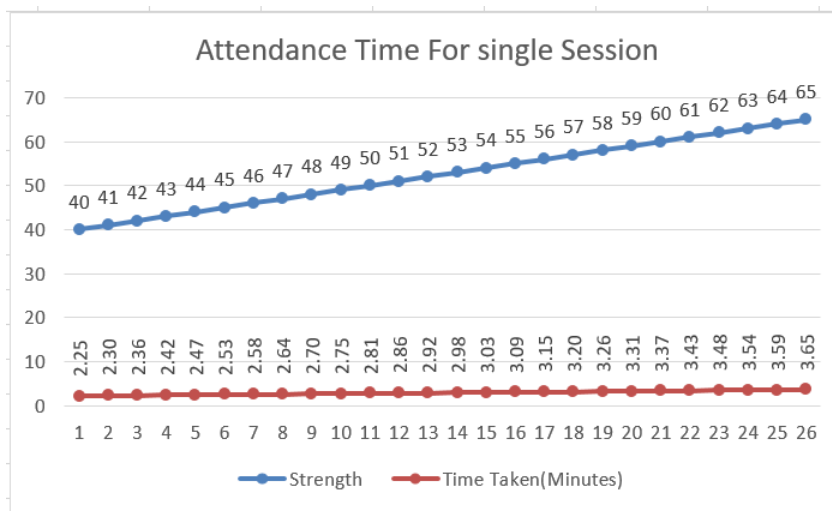

Figure 4: Time for a single session

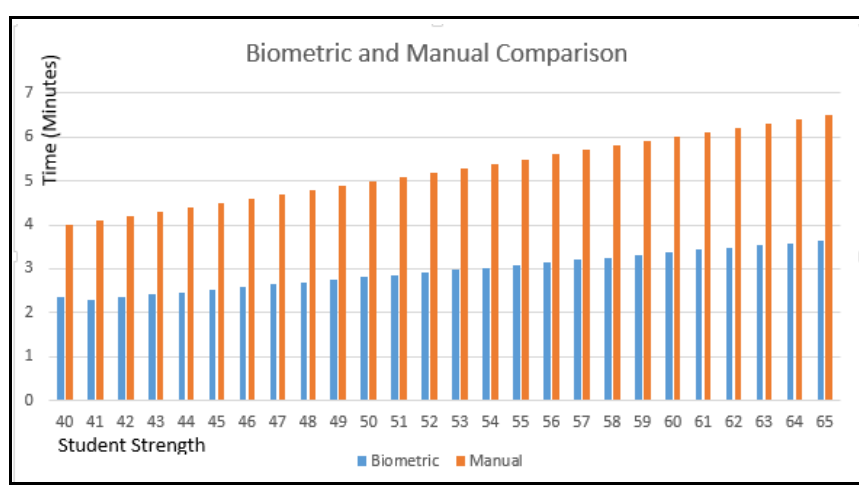

Figure 5: Comparison of Biometric and Manual System

The sample data captured in the database is shown in figure 3. The admin software is tested with this sample data and verified for notification to higher authorities through emailers. Also, the notification for parents is also tested by sending text SMS to the registered mobile numbers.

\section{CONCLUSION}

For Educational establishments, the Classroom Attendance Management System shows an answer for taking timely class attendance and can be utilized during examinations. The unique finger impression scanner gadget catches new fingerprints and makes layouts. For fingerprint coordinating, a client just needs to put the finger (or thumb) on the scanner, a picture is filtered, which is then looked at against the layouts previously put away in the database.

The proposed Access Control System (ACS) presents a versatile answer for identification and confirmation purposes. The nonexclusive idea of the ACS makes it conceivable to stretch out the framework to numerous areas and utilize the innovation in different circumstances.

\section{REFERENCES}

1. L. X. LI Jian-po, ZHU Xu-ning and Z. Zhi-ming, "Wireless fingerprint attendance system based on zigbee technology," in 2nd InternationalWorkshop on Intelligent Systems and Applications (ISA), May 2010, pp.1 - 4

2. Z. C. A. Kassem, M. Hamad and S. E. Dahdaah, "An rfid attendance and monitoring system for university applications," in 17th IEEE International Conference on Electronics, Circuits, and Systems (ICECS), 2010, pp. $851-854$.

3. Varun Chandrasekar, T.S.Natarajan, "Fingerprint Based Classroom Attendance Recording Device", International Journal on Recent and Innovation Trends in Computing and Communication, Volume: 2 Issue: 9, ISSN: 2321-8169, 2802-2805

4. Lim TS, Sim SC, Mansor MM. RFID based attendance system. 2009 IEEE Symposium on Industrial Electronics \& Applications (2009) Kuala Lumpur 778-782.

5. Yakub Saheed, Hambali Moshood, A Adedeji, Abdulmumeen, A Adeniji, I. Attendance Management System Using Barcode Identification on Students' Identity Cards (2016) The Pacific Journal of Science and Technology 17: 224-230.

6. Using smart card for secure physical access. A smart card alliance report, Smart card alliance Inc (2003) Princeton Junction, NZ.

7. Bevan S., Hayday S. "Attendance Management: a Review of Good Practice" Report 353, Institute for Employment Studies, December 1998.

8. C. Barral, "Biometrics \& Security," 2010, [Last accessed on 05 Jul 2015]. [Online]. Available: http://infoscience.epfl.ch/record/148685/ files/EPFL TH4748.pdf.

9. B. Institute, "Where are biometrics used?" 2015, [Last accessed on 07 Jul 2015]. [Online]. Available: http://www.biometricsinstitute.org/ pages/faq-3.html.

10. W. contributors, "Fingerprint recognition," 2015, [Last accessed on 05 Jul 2015]. [Online]. Available: https://en.wikipedia.org/w/index.php? title $=$ Fingerprint recognition\&oldid $=670123692$.

11. E. Spinella, "Biometric Scanning Technologies: Finger, Facial and Retinal Scanning," SANS GSEC, Online Submission, San Francisco, 2003.

Published By: 
12. S. Asha and C. Chellappan, "Biometrics: An Overview of the Technology, Issues and Applications," International Journal of Computer Applications, vol. 39, no. 10, pp. 35-52, 2012.

13. N. Manivannan, C. Tigli, A. Noor, and S. Memon, "Fingerprint Biometric for Identity management," International Journal of Industrial Engineering and Management, vol. 2, no. 2, pp. 39-44, May 2011

14. A. Jain, Y. Chen, and M. Demirkus, "Pores and Ridges: High-Resolution Fingerprint Matching Using Level 3 Features," IEEE Transactions on Pattern Analysis and Machine Intelligence, vol. 29, no. 1, pp. 15-27, Jan 2007.

15. ZKTeco, "F19," 2013, [Last accessed on 17 Jul 2015]. [Online]. Available: http://www.zktecoindia.com/products.php?prod=54

\section{AUTHORS PROFILE}

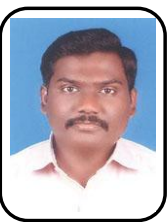

S Suprakash received his Bachelor degree in Computer Science and Engineering from Anna University by 2006. He has received his Master degree in VLSI Design from Anna University, 2008. He is working as an Assistant Professor in the Department of Information Technology, Kalasalingam Academy of Research and Education and also doing his research under the area Green Cloud Computing. He is the technical lead and undergoing many projects in reducing paper waste and automation. His areas of interest are Computing, Security, Data Management and Networks.

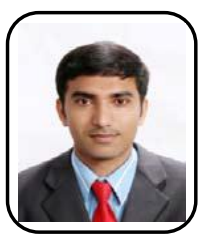

Balakannan S.P received his Ph.D. degree from the Department of Electronics and Information Engineering at Chonbuk National University, South Korea (2010). He has received his master degree (5 years integrated) from the Department of Computer Science and Engineering, Bharathiar University, India, in the year 2003. He has worked as a Project Assistant in Indian Institute of Technology (IIT), Kharagpur, India from 2003 to 2006. Currently, he is working as Assistant Professor in the Department of Information Technology, Kalasalingam Academy of Research and Education, Tamilnadu, India. His areas of interest include Wireless Network, Network Coding, Cloud \& Green Computing, Cryptography, and Mobile Communication. 